\title{
Expanding Horizon Of E-Governance In India And Its Policy Implication
}

\author{
Dr. Bikashdev Chhura ${ }^{1}$, Dr. P Marshal ${ }^{2}$, Ramakant Agarwal ${ }^{3}$ \\ ${ }^{3}$ Assistant Professors, NIMS University, Jaipur, Rajasthan \\ Email: ${ }^{1}$ bikashdev.chhura8@ gmail.com, ${ }^{2}$ princemarshal2326@gmail.com, ${ }^{3}$ rak111mu@gmail.com
}

\begin{abstract}
:
This paper purpose is to provide the clear vision of using ICT technology within the mainstream. The term ICT is quite new for the masses which is fully handle by the government. The government is keen focused for speed communication within the system so that work will faster, accountable, responsive and transparent. Moreover, government is trying to reduce the gap among the classes by adopting where each and all people can avail it. That is why Government has taken initiative many policy and program to achieve such concept. However, many hindrances may occurs to stop this concept such as bureaucracy and official systems. They fear the new technology on account in certain factors such as transparent, yes boss culture will eliminate and unemployment may reduce. However, government or any organization can assign man power wherever it necessary.
\end{abstract}

\section{Introduction:}

E- Governance is the application of Information and Communication Technology (ICT) by government in order to create simple, moral, accountable, responsive and transparent' (SMART) governance..The revolution in information and communication technology has brought a whole new agenda for governance into the realm of possibility. E-governance comprises decisional process and the use of ICT for wider participation of citizens in public affairs. Citizens are the participants in egovernance. The purpose of implementing e-governance is to improve government process and the delivery of public services to citizens. The "e" in e-governance stands for 'electronic'. E-governance is basically associated with carrying out the functions and achieving the results of through ICT. The reason why countries around the world are increasingly opting for e-governance is that governance has become more complex and varied in the last few decades and more competently citizen's expectations from government have increased.

Moreover, India being one of the largest countries in term of democratically, demographically and geographically; as stated, it still has gap of using govt. services to its large population. In this regards, there are still problems are existed to socio-economic prevailing in the country like unemployment, poverty, education, health, banking and business, etc. As a result, Government of India has launched various initiatives in order to overcome these problems with minimum government and maximum governance by enormous use of electronic devices. In support of it, every states, in the country, has launched different initiatives (projects of e-governance) in order to timely provide services to its huge population. In spite of this effective process, as said the issues above, retarding the success of egovernance to some extent. The present paper is going to discuss about evolution, initiatives, issues-challenges, and future prospects of e-governance in India.

E-Governance is not about ' $\mathrm{e}$ ' but about government. It is not about computers and websites, but about services to citizens and business.

E-governance is also not about translating process, it is about transforming them. Therefore E-governance is concerned with the transformation of government, modernization of government processes 
and functions and better public service delivery mechanisms through technology so that government can be put on an autopilot mode. E-Governance, in simple terms may be considered as the performance of the Government via electronic medium in order to facilitate an efficient, speedy and transparent process of disseminating information to the public and other agencies and also for performing other administrative activities of Governments.

Dr. A.P.J. Abdul kalam, former President of India, has visualized e-governance in the Indian context to mean: "A transparent smart e-governance aims at great access, secure and authentic flow of information crossing the interdepartmental barrier and provides a fair and unbiased service to the citizen."

\section{Major Challenges to E-Governance}

Dr. A.P.J Abdul Kalam, Former President of India and a visionary in the field of egovernance has aptly summarized the basic challenge lying before the country as the follows:

"E-Governance has to be citizen- friendly. Delivery of services to citizens is considered a primary function of the government. In a democratic nation of over one billion people like India, egovernance should enable seamless access to information and seamless flow of information across the state and central government in the federal set up. No country has so far implemented an e-governance system for one billion people. It is a big challenge before us."

The process of computerization for the implementation of Information Technology in major social, economic, political, scientific and commercial activities is not an undoubting task. The major challenges that system and designers face to is overcome the 'built in resistance' in the bureaucracy and official systems. They fear the new technology on account of three main factors:

1. With the introduction of computers and information technology, the bureaucratic setup and other allied systems will become more transparent;

2. The hierarchical organizational structure will be replaced by a more flattered one, the rule of the day or 'yes boss' culture will no longer survive the way it is today;

3. The implementation of new technology will render some important human resource element unemployed. The implementation of new technology will render some important human resource element unemployed.

The inhibitions about the new technology are because of lack of understanding of its strength, limitations and results it can yield. Other related problems are:

(i) Disparities in e-governance initiatives;

(ii) Lack of adequate infrastructure; (iii) Lack of access to technology in rural or remote areas and to the poor and the under privileged (iv) Lack of content in local languages (v) Low level literacy and lack of awareness among the people (vi) Lack of political will (vii) Lack of security of data.

Therefore, to make e-governance process a success, these and other related fears have to be dispelled at the earliest.

\section{The Intensifying Scope of E-Governance}

While e-governance cannot entirely replace and governance, even its limited applications are good enough to affect day- today living. It can fulfill roughly speaking, the four purposes for which citizens generally interact with the government:

1. Paying bills, taxes, fees and so on;

2. Registration formalities, whether a house purchase or a driving license.

Seeking information and

3. Lodging complaints.

E-Governance can reduce distances to nothing, linking remote villages to 
government offices in the cities, can reduce staff, cut costs, check leaks in the governing system, and can make the citizen- government interaction smooth, without queues and the tyranny of clerks. Despite these well- intentioned initiatives taken by the central and state governments, the system would not yield desired results unless the prerequisite of revamping of administrative structures facilitating these programs are established and education and training infrastructure developed to enable people to derive the maximum benefits out of these effects.

\section{E-Governance in India}

India is the world's seventh largest country and with a population of over one billion, is the world's second most popular state. There are 22 'official' languages, plus another 24 major languages, 720 dialects and 23 tribal languages. The scale of everything is huge and the starting point is very different and the problems are magnified, yet they are making good progress in information technology. Egovernance originated in India during the seventies with a focus on in government applications in the areas of defence, economic monitoring, planning and the deployment of ICT to manage data intensive functions related to elections, census, tax and administration. The establishment of National Informatics Centre (NIC) in 1977 was the first major step towards e-governance to connect all the district headquarters. The main thrust for e-governance was provided by the launching of NICNET in 1987 the national satellite-based computer Network. From the early nineties, e-governance has seen the use of IT for wider sectoral applications with policy emphasis on reaching out to rural areas and taking in greater inputs from Non -Governmental Organizations and private sectors as well. While recognizing information technology as a frontier area of knowledge in 1999 the Union Ministry of Information technology was created.
Concept of e-governance has gained momentum in last fifteen years in India. But today India is one of the front runners to achieved fully integrated e-governance by 2012. In 1998, Indian government formed IT task for initiating organized and serious efforts towards egovernance. The Central Government spends an amount of 25 billion yearly on implementation of e-governance projects. Lot of e-governance initiatives was taken around the country in the area of health, education, transport, agriculture, taxation and revenue, electronic commerce and business regulations and law enforcement and courts. The State Governments and Ministries of the Government of India have realized the potential of e-governance and are now very actively trying to implement

e-governance solutions. Some of these are already in full-blown implementation and have been outstanding successes. Many more at various stages of implementation while an even greater number are at a conceptual stage. These projects earned widespread appreciation, primarily for their ability to change the lives of citizens in the context of reduction in procedural delays, red-tapism and corruption, amidst increased participation and single window access. The government national common minimum program accords priority to improve the quality of basic governance and in that context proposes to promote egovernance on a "massive scale' in the areas of concern to the common people, keeping this priority, the department of information and technology has formulated the National E-Governance Plan (NEGP). NEGP presently consist of 10 components and 31 Mission Mode Projects (MMPs) in order to implement at the central, state and local government level joined with state government.

India has much gain from e-governance, especially when citizen participation in governance is one of the features of the fully evolved state of e-governance. Many e-readiness 
assessments have been carried out at the global levels that show the current state of India's e-readiness. United Nations E-Government Survey (2012), ranked India 125 with development index of 0.3829 , in 2010 India ranked as 119 with development index of 0.3567 . Though India has achieved many mile stones many more benchmarks are to be set in the area of e-governance. Presently e-governance initiatives have reached millions of people belonging to various sectors of society. Improved access to information and services has provided economic and social development opportunities, facilitated participation and communication in policy and decision-making processes and empowerment of the weakest groups. The success depends on many factors in e-governance that include the infrastructure, change in the human attitude and the changes in the legal framework.

\section{National e-Governance Plan}

A major initiative of the Government for ushering in e-Governance on national scale, called National e-Governance Plan (NeGP) was approved on 16 May 2006 with a vision to provide Public services to the common man in his locality at affordable costs. The NeGP is a multistakeholder programme which primarily focuses on making critical public services available and promoting rural entrepreneurship. The objective of NeGP is to transform traditional processes and service delivery mechanisms and create an environment that is citizen-centric, with rights based approach to governance while making interaction with Government easier, effective and transparent.

\section{Vision of NeGP}

The National e-Governance Plan (NeGP) has been conceptualized with the following vision:

"Make all Government services accessible to the common man in his locality, through common service delivery outlets and ensure efficiency, transparency and reliability of such services at affordable costs to realize the basic needs of the common man".

The National e-Governance Plan has been launched with the aim of improving delivery of government services to citizens and businesses and is guided by its vision. The vision statement clearly underlines accessibility, common service delivery outlets and successful implementation of e-governance applications by improving quality to satisfy its citizens. The vision has been designed keeping the rural population in mind. The need is to reach those sections of the society which have remained tangential to the government sphere due to various reasons like geographical challenges and lack of awareness. At present, citizens especially those living in remote rural areas have to travel long distance to avail a service through a government department or its local offices. This is a time-consuming and costly affair for the common man. To overcome this problem, as part of the $\mathrm{NeGP}$, one computer and internet enabled CSC is envisaged to be set up for every six villages so that villagers can easily avail these services. These CSCs are envisaged to offer online integrated service delivery on 'Anytime, Anywhere' basis. The use of ICT will enable the government to reach citizens thereby improving governance. This will also enable an improvement in the monitoring and implementing of various government schemes thereby increasing the accountability and transparency in government. E-governance helps in attaining this vision through the provision of citizen centric service delivery at nominal cost, and thereby providing better turnaround times and convenience in demanding and availing services.

\section{Mission Mode Projects}

A mission mode project (MMP) is an individual project within the National eGovernance Plan (NeGP) that focuses on one aspect of electronic governance, such 
as banking, land records or commercial taxes etc. Within NeGP, "mission mode" implies that projects have clearly defined objectives, scopes, and implementation timelines and milestones, as well as measurable outcomes and service levels. NeGP consists of 31 Mission Mode
Projects, encompassing 10 Central MMPs, 14 State MMPs and 7 integrated MMPs. Of the 31 MMPs, 24 have been approved by the Government of India. 19 MMPs have gone live and are delivering services electronically.

Table - 2.1 Mission Mode Projects

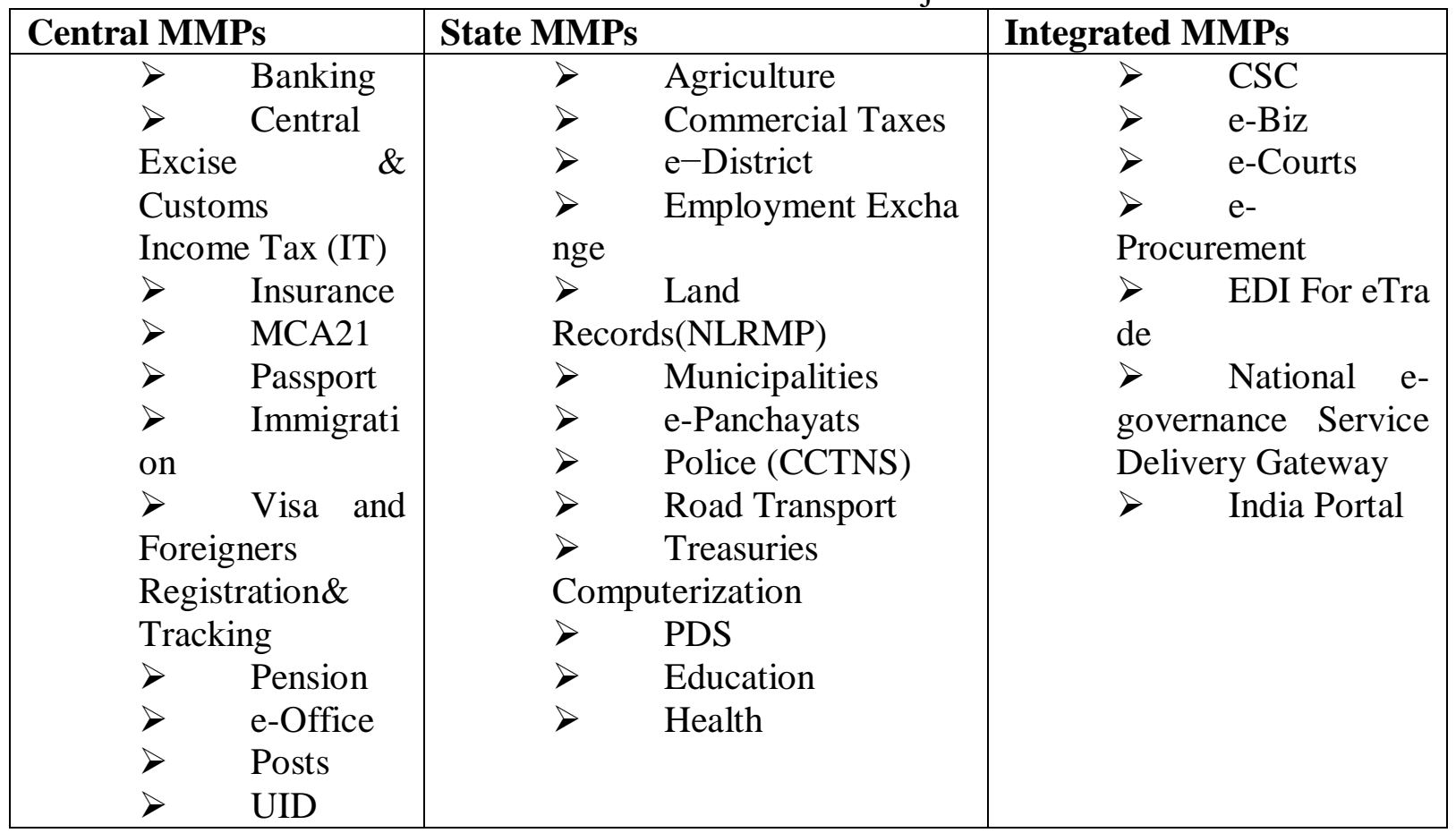

(Source: http://www.negp.com)

\section{National e-Governance Service Delivery Gateway}

The National e-Governance Plan (NeGP) of the Govt. of India aims to make all Government services accessible to the common man in his locality, through common service delivery outlets and ensure efficiency, transparency \& reliability of such services at affordable costs to realize the basic needs of the common man. One of the goals of the Government to meet this vision is the need to cooperate, collaborate and integrate information across different departments in the Centre, States and Local Government. Government systems characterized by islands of legacy systems using heterogeneous platforms and technologies and spread across diverse geographical locations, in varying state of automation, make this task very challenging. The National e-Governance Service Delivery Gateway (NSDG), a MMP under the NeGP, can simplify this task by acting as a standards-based messaging switch and providing seamless interoperability and exchange of data across. The National e-Governance Service Delivery Gateway (NSDG) is an attempt to reduce point to point connections between departments and provide a standardized interfacing, messaging and routing switch through which various players such as departments, front-end service access providers and back-end service providers can make their applications and data interoperable.

The National e-Governance Service Delivery Gateway (NSDG) aims to 
achieve a high order of interoperability among autonomous and heterogeneous entities of the Government (in the Centre, States or Local bodies), based on a framework of e-Governance Standards.

\section{E-Governance Policy}

The convergence of Information and Communication Technology (ICT) in the recent years has presented an opportunity for the Government to change the way the Government integrates, leverages and value sits information assets. With ease of access to information, targeted approach to mission delivery, enterprise resource management and Information Processing and dissemination - all of these can be raised to higher levels which in the past had a limited scope. Governments across the globe have realized that mere computerization alone will not realize the desired level of better Governance, as eGovernance includes People (Government staff and citizen), Process (Government Process Re-engineering) and Technologies (IT) which are all encompassing and hence the need for a separate e- Governance Policy. In many instances, Government departments might have come across shortage of resources in one department and excess of resources in another. This could be due to nonavailability of proper data and the required facilities to share available information. Even if Government departments are computerized and networked more for the purpose of internet usage and file/mail transfer, the information available in one department, which possesses the data, could not be utilized in other departments. This is because the information is stored in different formats, in different platforms and in different database systems.

By deploying the latest ICT, the Government departments can maximize access to the required information and also can bid farewell to the massive paper trail often associated with various Government agencies. Rather than providing non- detailed information to uninterested constituents, the Government departments can now direct the right information to the right people at the right time. Further, the enterprise-wide information can be an asset to the Government as well as to the entire population. This will help the departments in micro level analysis and informed decision-making. The service levels are increasing day by day. The service sector has become one of the important contributors for our Gross Domestic Product (GDP) and for the generation of newer employments. Many services, traditionally done by the Government through its own channels from its own offices are now demanded on public channels in multiple media deliveries and more importantly well beyond the regular working hours of the office.

A common man wants services to be enabled online in every possible way thereby establishing a channel to interact with the Government. Therefore there is a need for an e-Governance Policy to ensure that in the maze of activity there is consistency in approach. Interoperability, upgradeability, security and the like will need to be defined so as to prevent repetitive work in the field of application development.

\section{Common Service Centers}

Realizing the basic need of the common man, the Government has taken steps to provide all Government Services to the common man in his locality through Common Service Centres (CSCs). As of now, 1000 centres which include Common Service Centres and Primary Agriculture Cooperative Credit Societies (PACCS) are delivering the services. More new Common Service Centres will be rolled out by the Service Centre Agency (SCA) through an open tender process. The National e-Governance Plan (NeGP) formulated by the Government of India for implementation across the country, envisages the vision of making all 
Government services accessible to the common man in his locality through common service delivery outlets and ensure efficiency, transparency and reliability of such services at affordable costs. Accordingly, 5440 rural locations have been identified to establish these Common Service Centres in Tamil Nadu. $\mathrm{M} / \mathrm{s}$. SREI Infotech, one of the two Service Center Agencies, has launched the project successfully in 4 districts. The roll out and certification of Centres are progressing. Out of 5440, around 1000 centres have been fully rolled out and providing services to citizens. In other locations, the centres are being identified by the Service Center Agencies A State Portal on the State Portal Framework with online services is created and it will be utilized by the Common Service Centers for the benefit of the citizens.

The CSC's role is to provide all citizen centric services including Business-toCitizen services (B2C), Business-toBusiness services (B2B), Government-toCitizen Services (G2C) and Government to Government (G2G) services. It will act as a Citizen - Government Interface to provide services to rural citizens. Some of the range of services that may be offered through the CSCs include Agriculture, Banking, Education and Training, Telemedicine, Forms downloading, Ticket reservation, Digital photos, DTP work, Web Surfing, Photocopy, CD burning, etc. There is a huge potential for CSCs to act as data collection points in the village for research and government agencies. This could also increase the local employment opportunities in the village. The CSCs will be viewed as a front delivery point for delivery of end-to-end rural solutions.

With the growing importance of IT in the administration Odisha is making rapid strides to e-governance by making the state administration fully computerizes. Already several state government departments have computerized their internal management systems and several aspects of the public utility service. The following are the important e-governance projects implemented by the state government.

Although e-governance development initiatives are fast in Tamil Nadu there are many areas to be covered in the future. There is a need to properly identify the functions where it can be applied. Likewise, there is also need for proper devolution of responsibilities and development of broad guide lines and framework for enabling the implementation process at different level. There has to be special focus on monitoring the implementation of the egovernance policies, development of skills and attitudes. There is also need for adequate provision of financial and human resources to implement the e-governance application in various levels. 